\title{
PRODUCTIVITY OF A GASODYNAMIC LOOSENER
}

\author{
Ivan Dyakov', Valery Ivkin ${ }^{2}$ \\ 1, 2 Ulyanovsk State Technical University, Severny Venetz Str. 32, 432027 Ulyanovsk, Russia \\ E-mail: 1i.dyakov@ulstu.ru (corresponding author)
}

Received 19 January 2009; accepted 15 November 2010

\begin{abstract}
Maximum loads for a semi plane weakened by an aperture under uniform pressure were investigated for elaborating a mechanism for frozen ground destruction applying a recently designed loosener. Recommendations concerning the calculation of loosener productivity depending on the accepted technological scheme are given.
\end{abstract}

Keywords: frozen ground, gasodynamics, gas impulse, working body, productivity, loosener.

\section{Introduction}

The working rut of frozen ground has a wide variety of manufacturing methods constantly increasing volumes, high power consumption and cost. The problem of frozen ground is very urgent. The primary goal in building machine design is the improvement and modification of the existing work equipment and creation of new highly efficient mechanisms.

Along with an increase in the capacity of basic machines, the intensification of work processes is very perspective for increasing the efficiency of digging mechanisms.

The possibility of intensifying the process dealing with frozen grounds using a loosener by means of a gas impulse supplied to the zone of destruction provides the intensive destruction of the ground (Ивкин, Кузьмин 2003; Ивкин, Морозов 2004; Dyakov et al. 2007).

The destruction of the ground applying the energy of compressed gas supplied to a working body rather than to a mover is connected with the modification of machine design. Hence, there is a possibility of transferring considerable energy intended for ground destruction without increasing the basic weight and power of the machine.

\section{The Working Principle of a Gasodynamic Loosener}

The process of frozen ground destruction using a gasodynamic loosener embraces two stages.

The first stage of mechanical ground destruction is screwing up the working body into the estimated depth of loosening simultaneously filling up a working chamber with compressed air at high pressure.
The process of screwing up the working body into the estimated depth of loosening is based on the compatibility properties of frozen grounds. The consolidation of grounds takes place at the expanse of the destruction of cementing connections (ice-cement) between mineral particles and their reconfiguration due to more compact placement and movement to unbroken ground in axial and radical directions.

A shudder working body is pressed out by condensed ground and exhaust apertures are geometrized.

To decrease power consumption and increase the productivity of the loosening process at the closing stage of the first phase, an impulse of compressed air at high pressure is supposed to the destruction zone.

The compressed air contained in the working chamber is supplied to the zone of the contact of exhaust apertures along with the ground where cracks, cavities and various heterogeneities are always present and act as concentrators of tensions - the initiatory of ground destruction (see Fig. 1).

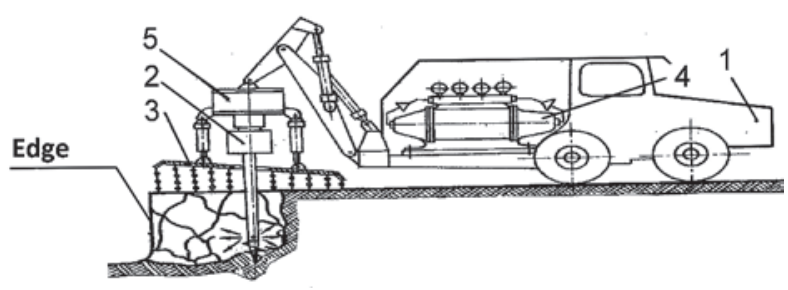

Fig. 1. A gasodynamic loosener based on a pneumatic tractor having a hydraulic drive of work equipment and an independent drive of acupressure installation: 1 - tractor; 2 working chamber of a gasodynamic loosener; 3 - protective screen; 4 -compressor installation; 5 - hydraulic engine 
Under the load of a gas impulse, tensions in the vicinity of crack tops caracal for frozen grounds appear. The compressed air at high pressure enters cracks acting as a wedge and crack surfaces move apart from each other.

A destruction cavity is formed and the area of the contact of compressed air with ground increases. It raises the efficiency of loosening frozen grounds by means of a gas impulse as the surface of the ground under the impact of the gas impulse increases.

Gasodynamic looseners have the simplest design and combine mechanical and gasodynamic methods used when working on frozen grounds (Ивкин, Кузьмин 2003; Ивкин, Морозов 2004; Dyakov et al. 2007).

\section{Scheme Units}

The area of loosening being considered is semi space with encircled departure and parallel to the edge of the impact. At loosening, the edge layers of the ground are deferred in the planes parallel to plane XOY (Fig. 2) as far as the depth of loosening is concerned.

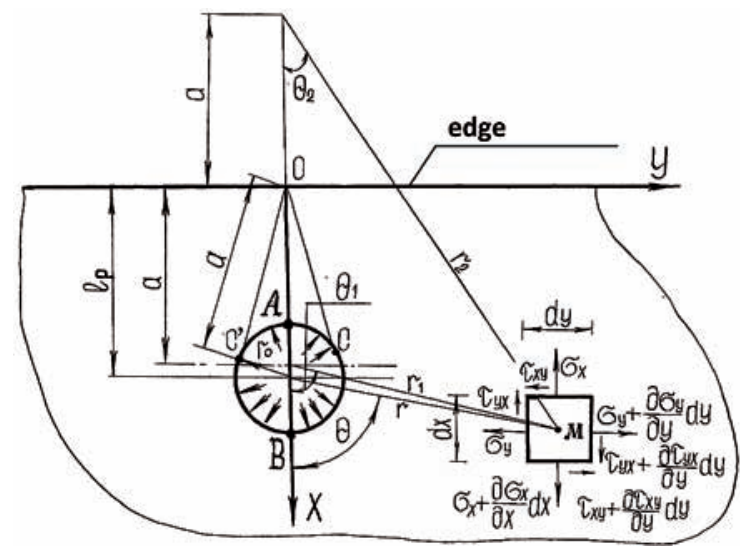

Fig. 2. The scheme estimating the distance up to the edge of the impact

Finding tension in the ground applying the preset gas impulse is required:

$$
\begin{aligned}
& \sigma_{x}=\partial^{2} \Psi / \partial y^{2} ; \\
& \sigma_{y}=\partial^{2} \Psi / \partial \tilde{o}^{2} ; \\
& \tau_{x y}=-\partial^{2} \Psi / \partial x \partial y,
\end{aligned}
$$

where: $\psi$ - the function of tension:

$$
\begin{aligned}
& \Psi=P \cdot r_{0}^{2} \cdot\left\{\left(l_{p} \cdot \lg r_{2} / r_{1}\right) / a+\right. \\
& x \cdot\left[\left(l_{p}-a\right) \cdot \cos \theta_{1} / r_{1}-\right. \\
& \left.\left.\left(l_{p}+a\right) \cdot \cos \theta_{2} / r_{2}\right] / a\right\} .
\end{aligned}
$$

In our case, $P$ is ground pressure in the initial period of destruction when the ground appears under the inference of the compressed air pressure the value of which is considered to be equal to pressure in the working chamber before its discharge (see Figs 1 and 2); $r_{0}-$ the radius of the circle cut in the ground using a screw blade of the loosener; $l_{p}$ - the distance between impact edge and the centre of the circle (Fig. 2); $a$ - the distance up to the radical axis numerically equal to the section of the tangent taken from the beginning of coordinates to the circle with radians $r_{0}$ :

$$
a=\sqrt{l_{p}^{2}-r_{0}^{2}}
$$

where: $r_{1}, r_{2}$ - radius vectors:

$$
\begin{aligned}
& r_{1}=\sqrt{(x-a)^{2}+y^{2}} ; \\
& r_{2}=\sqrt{(x+a)^{2}+y^{2}} .
\end{aligned}
$$

Tangents $-\operatorname{tg} \theta_{1}$ and $\operatorname{tg} \theta_{2}-$ can be expressed as:

$$
\begin{aligned}
& \operatorname{tg} \theta_{1}=y /(x-a) ; \\
& \operatorname{tg} \theta_{2}=y /(x+a),
\end{aligned}
$$

where: $x, y$ - are the current values of the abscissa and ordinate of point $M$ (see Fig. 2).

Let's geometrically represent complex number $z=x+i \cdot y$ as point $M$ where in the rectangular system of coordinates, axis $X$ (the axis of abscesses) is a material axis and axis $Y$ (the axis of ordinates) is an imaginary axis. form

We present radii vectors $r_{1}$ and $r_{2}$ in the complex

$$
\begin{aligned}
& z-a=r_{1} \cdot\left(\cos \theta_{1}+i \cdot \sin \theta_{1}\right)=r_{1} \cdot e^{i \cdot \theta_{1}} \\
& z+a=r_{2} \cdot\left(\cos \theta_{2}+i \cdot \sin \theta_{2}\right)=r_{2} \cdot e^{i \cdot \theta_{2}} .
\end{aligned}
$$

The inverted values of vector radii will be accordingly equal to

$$
\begin{aligned}
& 1 /(z-a)=\left(\cos \theta_{1}-i \cdot \sin \theta_{1}\right) / r_{1} \\
& 1 /(z+a)=\left(\cos \theta_{2}-i \cdot \sin \theta_{2}\right) / r_{2} .
\end{aligned}
$$

Let's designate in the function of complex variable

$$
f(z)=f(x+i \cdot y) \text {. }
$$

If $R[f(z)]$ is a material part and $\Phi[f(z)]$ is an imaginary part, then function $f(z)$ can be expressed as:

$$
f(z)=R[f(z)]+i \times \Phi[\mathrm{f}(\mathrm{z})] .
$$

Representing the function of tensions (see Eq. 2):

$$
\begin{aligned}
& \Psi=P \cdot r_{0}^{2}\left\{\left(l_{p} / a\right) \cdot R \cdot[\lg (z+a) /(z-a)]+\right. \\
& \left.(x / a) \cdot R \cdot\left[\left(l_{p}-a\right) /(z-a)-\left(l_{p}+a\right) /(z+a)\right]\right\} .
\end{aligned}
$$

From the complex variable function theory, the dependences are known as

$$
\frac{\partial \hat{O}[f(z)]}{\partial x}=-\frac{\partial R[f(z)]}{\partial y}=\hat{O}[\partial f(z) / \partial z] ;
$$




$$
\frac{\partial \Phi[f(z)]}{\partial x}=-\frac{\partial R[f(z)]}{\partial y}=\Phi[\partial f(z) / \partial z] .
$$

Let's calculate the derivative of the tension theory (see equation (14)):

$$
\begin{aligned}
& \partial \Psi / \partial x=-P \cdot r_{0}^{2}\{R \cdot[1 /(z-a)+1 /(z+a)]+ \\
& \left.(x / a) \cdot R \cdot\left[\left(l_{p}-a\right) /(z-a)^{2}-\left(l_{p}+a\right) /(z+a)^{2}\right]\right\} ;(17) \\
& \partial \Psi / \partial y=P \cdot r_{0}^{2}\left\{\left(l_{p} / a\right) \cdot \Phi \cdot[1 /(z-a)-1 /(z+a)]+\right. \\
& \left.(x / a) \cdot \Phi \cdot\left[\left(l_{p}-a\right) /(z-a)^{2}-\left(l_{p}+a\right) /(z+a)^{2}\right]\right\} .
\end{aligned}
$$

When applying the repeated differentiation, we will find out expressions of the corresponding tensions (see equation (1)):

$$
\begin{aligned}
& \sigma_{x}=\partial^{2} \Psi / \partial y^{2}= \\
& -P \cdot r_{0}^{2}\left\{\left(l_{p} / a\right) \cdot R \cdot\left[1 /(z-a)^{2}-1 /(z+a)^{2}\right]\right. \\
& \left.(2 \cdot x / a) \cdot R \cdot\left[\left(l_{p}-a\right) /(z-a)^{3}-\left(l_{p}+a\right) /(z+a)^{3}\right]\right\} ; \\
& \sigma_{y}=\partial^{2} \Psi / \partial x^{2}= \\
& P \cdot r_{0}^{2}\left\{( R / a ) \cdot \left[\left(2 \cdot a-l_{p}\right) /(z-a)^{2}+\right.\right. \\
& \left.\left(2 \cdot a+l_{p}\right) /(z+a)^{2}\right]+(2 \cdot x / a) \cdot R \cdot\left[\left(l_{p}-a\right) /(z-a)^{3}-\right. \\
& \left.\left.\left(l_{p}+a\right) /(z+a)^{3}\right]\right\} ; \\
& \tau_{x y}=-\partial^{2} \Psi / \partial y \cdot \partial x= \\
& P \cdot r_{0}^{2}\left\{F \cdot\left[1 /(z-a)^{2}+1 /(z+a)^{2}\right]+\right. \\
& \left.(2 \cdot x / a) \cdot F \cdot\left[\left(l_{p}-a\right) /(z-a)^{3}-\left(l_{p}+a\right) /(z+a)^{3}\right]\right\} .
\end{aligned}
$$

The components of the main tensions will be expressed accordingly:

$$
\begin{aligned}
& \left(\sigma_{y}+\sigma_{x}\right) / 2=P=\frac{\sigma_{p}\left(H_{p}^{2}-\frac{D^{2}}{4}\right)}{D^{2}} ; \\
& \left(\sigma_{y}-\sigma_{x}\right) / 2=P \cdot r_{0}^{2} \cdot\left\{R \cdot\left[1 /(z-a)^{2}+1 /(z+a)^{2}\right]+\right. \\
& \left.(2 \cdot x / a) \cdot R \cdot\left[\left(l_{p}-a\right) /(z-a)^{3}-\left(l_{p}+a\right) /(z+a)^{3}\right]\right\} \\
& \tau_{x y}=P \cdot r_{0}^{2}\left\{\Phi \cdot\left[1 /(z-a)^{2}-1 /(z+a)^{2}\right]+\right. \\
& \left.(2 \cdot x / a) \cdot \Phi \cdot\left[\left(l_{p}-a\right) /(z-a)^{3}-\left(l_{p}+a\right) /(z+a)^{3}\right]\right\} .
\end{aligned}
$$

When opening the expressions of the corresponding functions of complex variable $z$, we will get the equation in its final from:

$$
\begin{aligned}
& \left(\sigma_{y}+\sigma_{x}\right) / 2= \\
& P \cdot r_{0}^{2} \cdot\left\{\left[\left(l_{p}+a\right) / a\right] \cdot\left(\cos 2 \cdot \theta_{2} / r_{2}^{2}\right)-\right. \\
& \left.-\left[\left(l_{p}-a\right) / a\right] \cdot\left(\cos 2 \cdot \theta_{1} / r_{1}^{2}\right)\right\} ; \\
& \left(\sigma_{y}-\sigma_{x}\right) / 2= \\
& P \cdot r_{0}^{2} \cdot\left\{\left(\cos 2 \cdot \theta_{2}\right) / r_{2}^{2}+\left(\cos 2 \cdot \theta_{1}\right) / r_{1}^{2}+\right. \\
& 2 \cdot x \cdot\left[\left(l_{p}-a\right) / a\right) \cdot\left(\cos 3 \cdot \theta_{1} / r_{1}^{3}\right)- \\
& \left.\left[\left(l_{p}+a\right) / a\right] \cdot\left(\cos 3 \cdot \theta_{2}\right] / r_{2}^{3}\right\} ;
\end{aligned}
$$

$$
\begin{aligned}
& \tau_{x y}=-P \cdot r_{0}^{2} \cdot\left\{\left(\sin 2 \cdot \theta_{2} / r_{2}^{2}\right)+\left(\sin 2 \cdot \theta_{1} / r_{1}^{2}\right)+\right. \\
& 2 \cdot x \cdot\left[\left(l_{p}-a\right) / a\right) \cdot\left(\sin 3 \cdot \theta_{1} / r_{1}^{3}\right)- \\
& \left.\left.\left[\left(l_{p}+a\right) / a\right)\right] \cdot\left(\sin 3 \cdot \theta_{2} / r_{2}^{3}\right)\right\} .
\end{aligned}
$$

While investigating the process of ground loosening, we take a particular interest in the distribution of tension along driving at the edges.

Boundary conditions in such cases will be expressed as:

$$
\begin{aligned}
& x=0 \\
& \theta_{1}+\theta_{2}=\pi \\
& r_{1}=r_{2}=\sqrt{a^{2}+y^{2}} .
\end{aligned}
$$

When substituting dependences $(28,29,30)$ in equations $(25,26,27)$ and making transformations, we will get:

$$
\begin{aligned}
& \tau_{x y}=0 ; \\
& \sigma_{x}=0 ; \\
& \lrcorner_{y} \downarrow\left[\begin{array}{lllll}
4 & P & r_{0}^{2} & \left.\left(\begin{array}{lll}
a^{2} & y^{2}
\end{array}\right)\right] /\left(\begin{array}{ll}
a^{2} & y^{2}
\end{array}\right)^{2} .
\end{array}\right.
\end{aligned}
$$

In section $-a<y<a$, the external side (a drive at the edge) is stretched. Stretching maximum takes place at the side point on symmetry axis $(x=0 ; y=0)$ and substituting dependence ( 3 ) in equation (33) equals to:

$$
\sigma_{y}^{\max }=4 \cdot P \cdot r_{0}^{2} /\left(l_{p}^{2}-r_{0}^{2}\right) \text {. }
$$

At $y>a$, the ground in the vicinity of the agreed surface is subjected to compression. The maximum compression occurs at points:

$$
y= \pm \sqrt{3} \cdot a \text {. }
$$

When substituting dependences (3) and (35) in equation (33), we will get:

$$
\sigma_{y}^{\min }=-(P / 2) \cdot r_{0}^{2} /\left(l_{p}^{2}-r_{0}^{2}\right) .
$$

Equation (33) shows only stretching tensions acting in the vicinity of the free surface. The tension of compression equals zero.

Thus, ground loosening is possible in case if:

$$
\sigma_{y}^{\max } \geq \sigma_{p}
$$

where: $\sigma_{p}$ - the durability of frozen ground at rupture.

Solving equations (34) and (37) will help with finding the distance up to driving at the edge:

$$
l_{p}=r_{0} \sqrt{\left(4 \cdot P / \sigma_{p}\right)+1} \text {. }
$$

The imperfection degree of a building car intended for frozen ground loosening is estimated from equation:

$$
C_{H}=\frac{X}{\sigma_{p}},
$$

where: $X$ - the general resistibility of frozen ground to destruction using the building car; $\sigma_{p}$ - the resistibility of frozen ground to the destruction at rupture (see Table 1); 
The greater is the ratio in equation (39), the more power consuming method of frozen ground loosening is employed in loosener design in comparison with the method based on rupture defamation (separation of the ground from the file).

If we take the value of the specific resistance of frozen ground to rupture as a unit, the rations of resistivity to other kinds of destruction deformation will be the following (see Table 1):

Table 1. The ratio of the resistivity of frozen grounds to different kinds of destruction

\begin{tabular}{cc}
\hline Type of deformation & Relative coefficient \\
\hline Rupture & 1 \\
\hline Shear & 1.5 \\
\hline Lending & 2 \\
\hline Compression & 3 \\
\hline Cutting & $7-11$ \\
\hline Pressing in & 21 \\
\hline
\end{tabular}

Technical decisions (Ивкин, Кузьмин 2003; Ивкин, Морозов 2004; Dyakov et al. 2007) allow to realize the least power consuming method of loosening (separation of the ground from the file) at the expanse of supply to the zone of loosening rather than considering high energies of the compressed air at high pressure. The energy of the compressed air is transferred to the ground being loosened directly while it may be considered as a material being processed by an action of a gas impulse. The purpose of investigations is to establish the productivity of the geodynamic loosener.

\section{The Results of Investigations}

Digging cars equipped with gas impulse facilities are the most perspective and convenient method of activating the loosening process from the point of view of practicability (Ивкин, Кузьмин 2003; Ивкин, Морозов 2004; Dyakov et al. 2007) know:

To design gas impulse facilities, it is necessary to

- the pressure of the compressed gas in the working chamber;

- the capacity of the working chamber depending on the set ground conditions and the depth of loosening.

Let's consider the most general variant of calculation when the initial parameters of the loosener are:

- the depth of loosening $H_{p}$;

- ground conditions characterized by rupture durability;

- the capacity of base machine engine $N_{g}$.

The depth of frozen ground loosening is taken equal to the distance up to driving at the edge (see Figs 1 and 2):

$$
H_{p}=l_{p} .
$$

We have established a close linear relation between the readings of density meter $C_{u d}$ providing an integral estimation of frozen ground durability and a more definite value of the durability of frozen ground at rupture:

$$
\sigma_{\partial}=0.04 \cdot \tilde{N}_{u d}+0.001 \cdot \tilde{N}_{u d}^{2} .
$$

A dynamic density meter more commonly referred


plied in road building to estimate the carrying capacity of ground roads. The device represents a cylindrical core with a cross section of $1 \mathrm{~cm}^{2}$ on which the load weighing $2.5 \mathrm{~kg}$ is placed. Falling from the height of $0.4 \mathrm{~m}$, load strikes a persistent washer mounted on the core forcing it to drive into the ground.

Work of each strike equals $10 \mathrm{~J}$. Work necessary for the tip to drive into the ground at the depth of $10 \mathrm{~cm}$ is a conventional criterion of frozen ground durability.

Excessive air pressure in the working chamber is calculated as provided in equation (38):

$$
P=\frac{\sigma_{p}\left(H_{p}^{2}-\frac{D^{2}}{4}\right)}{D^{2}},
$$

where: $\sigma_{p}$ - the durability of frozen ground at rupture; $H_{p}$ - the depth of ground loosening; $D$ - the diameter of a screw blade of the working body (see Fig. 3):

$$
D=60 \cdot \sqrt[3]{N_{g}-N_{k}}[\mathrm{~mm}],
$$

where: $N_{g}$ - the capacity of a base machine, KW; $N_{k}$ - power consumed by a compressor drive, KW (a compressor may by positioned on the base machine taking into account its dimensions and weight).

The basic technical characteristics of high pressure compressors are given in Table 2.

Compressors DK-2 and DK-10 have an independent drive and their application in gasodynamic looseners are more preferable as if it is possible to exclude value $N_{k}$ intended for a compressor drive in equation (43). Hence, the diameter of the screw blade of the working body increases.

The capacity of the working chamber is calculated by equation (44):

$$
V=\frac{A_{\text {gas }}(K-1)}{P\left[1-\left(\frac{P_{1}}{P}\right)^{\frac{K-1}{K}}\right]},
$$

where: $A_{g a s}$ - work performed by the compressed air at its adiabatic expiration from the working chamber:

$$
A_{g a s}=A_{p r} \cdot K_{N} ;
$$

$A_{p r}$ - work performed by a gas impulse; $K_{N}$ - the factor considering changes in the capacity of a gas impulse depending on the cross section of the working body; $P$ - excessive air pressure in the working chamber before its discharge; $P_{1}$ - the final pressure of extending air; $K=1.41-$ the adiabatic value. 
Table 2. Technical characteristics of high pressure compressors

\begin{tabular}{|c|c|c|c|c|c|c|c|}
\hline \multirow{2}{*}{$\begin{array}{l}\text { Compressor types } \\
\text { (produced in } \\
\text { Russia) }\end{array}$} & \multirow{2}{*}{$\begin{array}{l}\text { Capacity of air } \\
\text { forcing, } 1 / \mathrm{min}\end{array}$} & \multirow{2}{*}{$\begin{array}{c}\text { Pressure of } \\
\text { air forcing, } \\
\mathrm{MPa}\end{array}$} & \multirow{2}{*}{$\begin{array}{c}\text { Power } \\
\text { consumption, } \\
\mathrm{kW}\end{array}$} & \multicolumn{3}{|c|}{ Overall dimensions, $\mathrm{mm}$} & \multirow{2}{*}{ Mass, $\mathrm{kg}$} \\
\hline & & & & length & width & height & \\
\hline KW D-1.6 & 2.2 & 15.0 & 8.0 & 580 & 310 & 710 & 170 \\
\hline K2-150 & 2.0 & 15.0 & 8.0 & 430 & 450 & 490 & 85 \\
\hline $\mathrm{IK}$ & 8.0 & 20.0 & 26.0 & 885 & 825 & 1295 & 700 \\
\hline K-5 & 16.0 & 22.5 & 50.0 & 1200 & 1080 & 1820 & 1350 \\
\hline K-6 & 8.0 & 22.5 & 35.0 & 850 & 580 & 1355 & 600 \\
\hline K-7 & 6.5 & 22.5 & 26.0 & 832 & 585 & 1000 & 445 \\
\hline DK-2 & 8.0 & 23.0 & 47.0 & 2200 & 890 & 860 & 820 \\
\hline $\mathrm{DK}-10$ & 9.0 & 40.0 & 96.0 & 2200 & 890 & 860 & 820 \\
\hline EK-15-M & 16.0 & 20.0 & 42.0 & 1185 & 860 & 1535 & 1200 \\
\hline
\end{tabular}

Work of a gas impulse necessary for ground loosening is calculated by equation:

$$
A_{p r}=\left[\frac{\left(H_{p}-H_{0}\right) \cdot K_{o b}}{K_{\omega} \cdot K_{u d}^{t}}\right]^{2},
$$

where: $H_{p}$ - the depth of ground lessening; $H_{0}$ - the minimum depth at which ground loosening begins:

$$
H_{0}=(1.0 \div 2.0) \cdot D \text {, }
$$

$K_{\omega}, K_{u d}^{t}$ - the factors considering value humidity and the temperature of frozen grounds influencing the efficiency of their destruction by a gas impulse; $K_{o b}$ - the factor considering the quantity of bared surfaces.

At ground loosening (see Fig. 1), we have:

- the loosener positioned on the surface free from snow;

- the surface forward to which ground loosening is performed.

The surface must be prepared in advance. $K_{o b}$ equals 0.7 when the loosener moves towards the edge, otherwise $K_{o b}$ is equal to 1 .

The factor considering changes in gas impulse capacity is calculated by equation:

$$
K_{N}=\frac{F_{e}}{F_{f}},
$$

where: $F_{e}=214.4 \mathrm{~mm}^{2}$ - the passage cross section of a working body taken as a standard; $F_{f}$ - the actual passage cross section of a working body depending on the internal diameter of saddle $\mathrm{B}$ and the diameter of cube $d_{m p}$ bringing compressed air to the chamber controlling a valve (see Fig. 3):

$$
F_{f}=\frac{\pi d_{c}^{2}}{4}-\frac{\pi d_{m p}^{2}}{4}
$$

The technological scheme of frozen ground loosening is shown in Fig. 4.

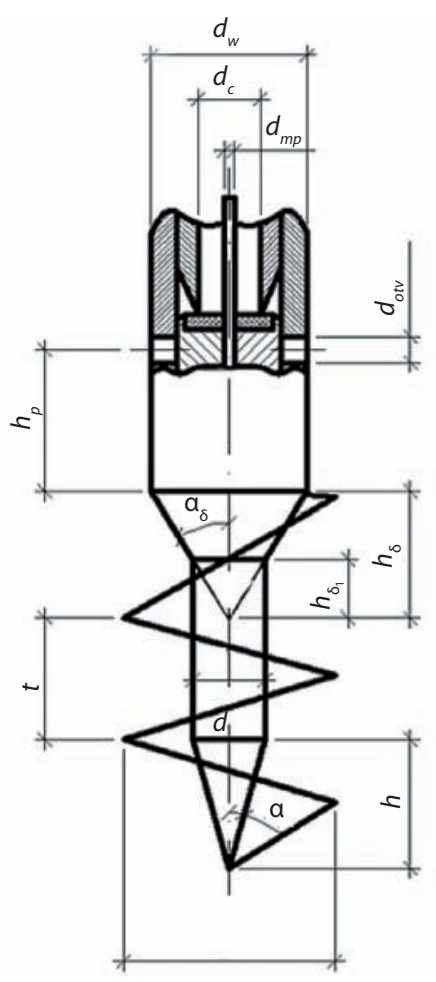

Fig 3. A variant of the designed bottom part of the working body of the loosener

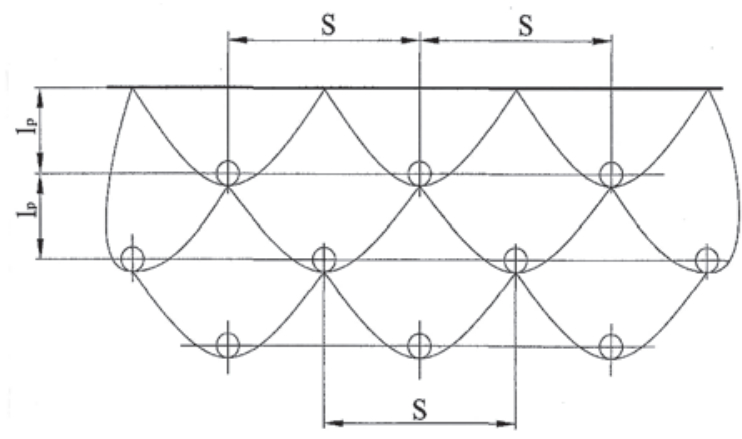

Fig 4. The technological scheme of frozen ground loosening using a gasodynamic loosener 
A working body is positioned at the distance of $l_{p}=H_{p}$ from the edge. Step oppositions $S$ are calculated by equation:

$$
S=4.0 \cdot H_{p}
$$

where: $H_{p}$ - the depth of loosening.

The productivity of the loosener may be calculated applying equation (51):

$$
\Pi=60 \cdot H_{p} \cdot S \cdot l_{p} \frac{K_{b}}{t_{c}},
$$

where: $H_{p}$ - the depth of loosening; $\mathrm{S}$ - the step of positions (see Fig . 4 ); $l_{p}$ - the distance between the lines of positions; $K_{b}$ - the factor of machine functioning during a period of time; $t_{c}$ - the length of the cycle calculated by equation (52):

$$
\begin{aligned}
& t_{c}=t_{n}+t_{n . p .}+\frac{H_{z a v}}{t \cdot n_{b}}+ \\
& \frac{H_{p o d}}{v_{o n}}+\frac{\left(H_{z a v}+H_{p o d}\right)}{v_{n}},
\end{aligned}
$$

where: $t_{n}$ - time necessary for changing work positions; $t_{n . p .}$ - time necessary for controlling mechanisms switching them on and off; $H_{z a v}$ - the depth of the loosener screwing into the ground; $t$ - the step of a screw blade (see Fig. 3); $n_{b}$ - the frequency of equipment; $H_{\text {pod }}$ the height of lifting work equipment above the ground level; $v_{\text {on }}$ - the velocity of inserting work equipment; $v_{n}$ - the velocity of extracting work equipment.

\section{Conclusions}

1. The necessity of looking for effective methods of frozen ground loosening and the creation of high efficiency equipment for operation in winter periods of a building is due to the equipment of all year round excavations. The analysis of constructive and patent decisions on the working bodies of a traditional digging machine as well as on a gas impulse has shown that a gasodynamic loosener can be the most perspective machine for making the processes of frozen grounds loosening more active. The reasons are the following:

- Vibration and dynamic loadings do not influence the equipment both during the process of screwing up into frozen ground and at the discharge of the working chamber. This fact predetermines its high operational reliability and improvement for an operator under working conditions.

- The simplicity of variation in a loosening mode in a wide range of excessive pressures in the working chamber.

- The simplicity of design and the possibility of installation on a serial small-sized dredger or tractors having pneumatic wheels.

- High power of gasodynamic equipment allows increasing productivity and decreasing material consumption in comparison with designs of a traditional type.
2. The lows of frozen ground destruction and the following equation for calculating the depth of loosening are formulated. Thus, the initial parameters should be pressure in the working chamber, the diameter of a screw blade of working equipment and the durability characteristics of frozen grounds at rupture.

3. Experimental researches have confirmed the usefulness of the method making frozen ground loosening more intense when applying the gasodynamic loosener and working capacity of the equipment used in a wide range of negative air temperatures $\left(-33 \div 0{ }^{\circ} \mathrm{C}\right)$ and compressed air pressures (reaching $22.5 \mathrm{MPa}$ ). The application of the gasodynamic loosener is expedient for loosening sandy. Both loamy and clay ground are homogenous and contain gravel and story particles (up to $40 \%$ ).

\section{References}

Dyakov, I.; Ivkin, V.; Popovich, A. 2007. A soil loosening machine of ripper for winter earth-moving in transport construction, Transport 22(4): 316-319.

Ивкин, В. С.; Кузьмин, Е. К. 2003. Газодинамический рыхлитель. Патент Российской Федерации № 2244784, МПК E02F5/32 [Ivkin, V. S.; Kuzmin, E. K. Gasodynamic Loosener. Patent of the Russian Federation] (in Russian).

Ивкин, В. С.; Морозов, В. В. 2004. Устройство для разрушения прочных и мерзлых грунтов. Патент Российской Федерации № 2276235, МПК Е02F5/30 [Ivkin, V. S.; Morozov, V. V. Equipment for frozen ground destruction. Patent of the Russian Federation] (in Russian). 